Article

\title{
Retrieval of Particulate Backscattering Using Field and Satellite Radiometry: Assessment of the QAA Algorithm
}

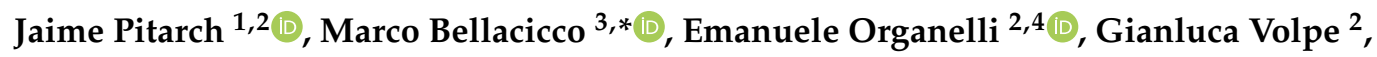 \\ Simone Colella ${ }^{2}$, Vincenzo Vellucci ${ }^{5}$ (D) and Salvatore Marullo ${ }^{2,3}$ (D) \\ 1 Department of Coastal Systems, NIOZ Royal Netherlands Institute for Sea Research and Utrecht University, \\ 1790 Texel, The Netherlands; jaime.pitarch@nioz.nl \\ 2 Istituto di Scienze del Mare (ISMAR)-CNR, Via Fosso del Cavaliere, 100 Rome, Italy; \\ emanuele.organelli@artov.ismar.cnr.it (E.O.); gianluca.volpe@cnr.it (G.V.); simone.colella@cnr.it (S.C.) \\ 3 Energy and Sustainable Economic Development (ENEA), Italian National Agency for New Technologies, \\ 00044 Frascati, Italy; salvatore.marullo@enea.it \\ 4 Laboratoire d'Océanographie de Villefranche (LOV), Sorbonne University, CNRS, \\ 06230 Villefranche-sur-Mer, France \\ 5 Institut de la Mer de Villefranche (IMEV), Sorbonne University, CNRS, F-06230 Villefranche-sur-Mer, France; \\ enzo@obs-vlfr.fr \\ * Correspondence: marco.bellacicco@enea.it
}

Received: 29 November 2019; Accepted: 20 December 2019; Published: 24 December 2019

\begin{abstract}
Particulate optical backscattering $\left(b_{b p}\right)$ is a crucial parameter for the study of ocean biology and oceanic carbon estimations. In this work, $b_{b p}$ retrieval, by the quasi-analytical algorithm (QAA), is assessed using a large in situ database of matched $b_{b p}$ and remote-sensing reflectance $\left(R_{r s}\right)$. The QAA is also applied to satellite $R_{r s}$ (ESA OC-CCI project) as well, after their validation against in situ $R_{r s}$. Additionally, the effect of Raman Scattering on QAA retrievals is studied. Results show negligible biases above random noise when QAA-derived $b_{b p}$ is compared to in situ $b_{b p}$. In addition, $R_{r s}$ from the CCI archive shows good agreement with in situ data. The QAA's functional form of spectral backscattering slope, as derived from in situ radiometry, is validated. Finally, we show the importance of correcting for Raman Scattering over clear waters prior to semi-analytical retrieval. Overall, this work demonstrates the high efficiency of QAA in the $b_{b p}$ detection in case of both in situ and ocean color data, but it also highlights the necessity to increase the number of observations that are severely under-sampled in respect to others environmental parameters.
\end{abstract}

Keywords: particulate optical backscattering; Raman scattering; QAA algorithm; ESA OC-CCI

\section{Introduction}

Retrieval of water inherent optical properties (IOPs) from both field and ocean color radiometry is at the base of several biogeochemical and physical oceanographic studies [1,2]. IOPs of algal and non-algal particles can be derived from remote sensing reflectance spectra $\left(\mathrm{R}_{\mathrm{rs}}\right.$; units of $\left.\mathrm{sr}^{-1}\right)$ by using appropriate algorithms [3-5]. Among IOPs, the particulate optical backscattering coefficient $\left(b_{b p}\right.$; in $\left.\mathrm{m}^{-1}\right)$ is related to the particle concentration in seawater, on their size distribution, refractive index, shape and structure [6-8]. Former research suggested that $b_{b p}$ is mostly influenced by submicron non-algal particles [9-11]. However, it has been recently shown that most of $b_{b p}$ is due to particles with equivalent diameters between 1 and $10 \mu \mathrm{m}$ [8], thus including the contribution of phytoplankton cell and supporting the use of $b_{b p}$ for the retrieval of: (i) particulate organic concentration (POC) [12,13]; (ii) particle size distribution [14,15]; and (iii) phytoplankton carbon biomass concentration $\left(\mathrm{C}_{\text {phyto }} ; \mathrm{mg} \mathrm{m}^{-3}\right)$ [16-18], 
a key parameter also for phytoplankton physiology studies $[2,19,20]$. Efficiency in the $b_{b p}$ retrieval is crucial for ocean biology and global ocean carbon estimations.

On one hand, radiative transfer theory provides the link between $b_{\mathrm{bp}}$ and optical radiometry [21]. Therefore, inversion algorithms for $b_{\mathrm{bp}}$ detection from optical radiometry can be developed. In particular, the quasi-analytical algorithm $[3,22]$ is a multi-level algorithm that concatenates a sequence of empirical, analytical, and semi-analytical steps to retrieve spectral total non-water light absorption and backscattering $\left(\mathrm{a}_{\mathrm{nw}}\right.$ and $\mathrm{b}_{\mathrm{bp}}$ ) first and to decompose $\mathrm{a}_{\mathrm{nw}}$ into its CDOM, algal and non-algal contributions. Specifically, about $b_{\mathrm{bp}}$, some studies suggested some degree of $b_{\mathrm{bp}}$ overestimation by the QAA [23,24], but their reference $b_{\mathrm{bp}}$ data were sub-products of chlorophyll-a (Chl) measurements. QAA estimations from satellite $\mathrm{R}_{\mathrm{rs}}$ showed a bias of $+16.4 \%$ with respect to in situ $\mathrm{b}_{\mathrm{bp}}$ for the Adriatic Sea [25]. Using the in situ NOMAD dataset [26], $a b_{b p}$ overestimation of $+38 \%$ by the QAA with respect to the observed value was reported [27]. Other results, based on in situ matchups, showed a bias of $+2.5-8.8 \%$ for the QAA-derived $b_{\mathrm{bp}}$ in Arctic waters, and of $+9.5 \%$ to $+16.4 \%$ in low-latitude waters [28]. Pitarch et al. [29] reported a slight underestimation within 10\% in the Mediterranean Sea. Most recently, QAA-derived $b_{\mathrm{bp}}$ from different satellite sensors (i.e., MODIS, VIIRS, OLCI) showed good performance with respect to a large in situ $b_{\mathrm{bp}}$ dataset collected on biogeochemical (BGC)-Argo floats [30].

Currently, in the European Space Agency (ESA) Ocean Colour (OC) Climate Change Initiative $(\mathrm{CCI}), \mathrm{QAA}$ is the selected algorithm to retrieve $\mathrm{b}_{\mathrm{bp}}$. Specifically, the ESA OC-CCI project aims at creating a long-term, consistent, uncertainty-characterized time series of ocean color products, for use in climate-change studies [5,31]. In such a context, while in the case of $\mathrm{Chl}$ the uncertainties are fully provided, the $b_{\mathrm{bp}}$ satellite products lack such information that is also crucial for POC and $\mathrm{C}_{\text {phyto }}$ estimations [1,32]. This absence of statistical assessment is influenced by the paucity of a sufficient number of in situ observations for the determination of uncertainties.

Nowadays, the uncertainties associated to QAA-based $b_{b p}$ retrievals globally are not known. In order to provide a best-effort $b_{b p}$ uncertainty assessment, this work aims at evaluating the efficiency of QAA for global $b_{\mathrm{bp}}$ retrievals by using a large database of corresponding in situ $\mathrm{R}_{\mathrm{rs}}$ and $\mathrm{b}_{\mathrm{bp}}$ data $(N=2881)$. In details, we use the updated version of the recent in situ global bio-optical dataset [33] together with field measurements from the BOUSSOLE buoy [34] and two different oceanographic cruises in the Tyrrhenian and Adriatic Seas. Unlike previous studies [29], here, the QAA performance is considered at multiple bands that further allow the evaluation of the $b_{\mathrm{bp}}$ spectral slope retrievals against in situ measurements. The goals of this paper are thus: (i) to define the accuracy of the QAA for $b_{b p}$ retrievals using only in situ $R_{r s}$ data; (ii) to validate the $C C I R_{r s}$ with in situ corresponding data; and (iii) to evaluate the performance of the QAA using satellite $C C I R_{r s}$ as input data.

\section{Data and Methods}

\subsection{Assessment of the Quasi-Analytical Algorithm (QAA)}

The original algorithm [3] has undergone many updates and developments by several researchers. The QAA version here used is based on the algorithm for the CCI bands which is currently integrated in the SeaWiFS data analysis system (SeaDAS) [22].

The sub-surface $\mathrm{R}_{\mathrm{rs}}$ (named $\left.r_{r s}\right)$ is calculated as $r_{r s}=R_{r s} /\left(0.52+1.7 R_{r s}\right)$ and modeled as a function of the IOPs as: $r_{r s}=g_{0} u+g_{1} u^{2}$, with $u=b_{b} /\left(a+b_{b}\right), \mathrm{g}_{0}=0.089$ and $\mathrm{g}_{1}=0.1245$. This approach provided good results in the Mediterranean Sea in case of oligotrophic and coastal waters [29,35].

The QAA uses an empirical inversion of $R_{\mathrm{rs}}$ to retrieve absorption and then it solves total backscattering $\left(b_{b}\right)$ analytically. $b_{b p}$ is calculated by subtraction of pure seawater backscattering $\left(b_{b w}\right)$ for an average temperature of $14^{\circ} \mathrm{C}$ and an average salinity of 38 PSU [36]. $b_{\mathrm{bp}}$ is first estimated at 
a reference wavelength of $\lambda=555 \mathrm{~nm}$ and then the calculation is extended to other wavelengths by assuming a power law $b_{b p}=b_{b p}\left(\lambda_{0}\right)\left(\lambda / \lambda_{0}\right)^{-\eta}$ for the $b_{\mathrm{bp}}$ with a spectral slope.

$$
\eta=p_{1}\left[1-p_{2} \exp \left(-p_{3} \frac{r_{r s}(443)}{r_{r s}(555)}\right)\right]
$$

Equation (1) is widely used for QAA retrievals of $b_{b p}$ at multiple wavelengths. Nevertheless, we use the in situ dataset presented here to evaluate the accuracy of analytical $\eta$. The functional form of Equation (1) is used and the default numerical coefficients $p_{1}=2.0, p_{2}=1.2$ and $p_{3}=0.9$ [22] are replaced by unknown variables established by non-linear regression. To this aim, we used the iterative bi-square method, which minimizes a weighted sum of squared errors, where the weight given to each data point decreases with the distance from the fitted curve [37]. This procedure makes the curve sensitive to the bulk of the data and the effect of outliers is reduced. The error function is minimized through the trust region algorithm [38]. In addition, the $95 \%$ confidence prediction bounds are also computed.

It is known that for oligotrophic waters the Raman scattering plays a significant role that is not accounted for in the semi-analytical $R_{r s}$ modeling [39]. Therefore, a pertinent question is how much this phenomenon affects the semi-analytical $b_{\mathrm{bp}}$ retrievals. With this aim, Lee et al. [40] developed empirical correction formulas to compensate the Raman scattering on the $\mathrm{R}_{\mathrm{rs}}$. Here, we assess the effects of this compensation on the difference between the in situ $b_{b p}$ and $R_{r s}$-derived $b_{b p}$. The statistical assessment was also replicated in other different cases: (i) validation of satellite CCI $R_{r s}$ against in situ $R_{r s}$; and (ii) $b_{b p}$ retrievals after the application of QAA to satellite $R_{r s}$ (Raman corrected), were compared to in situ measurements at the different available wavelengths.

Estimated data $y_{i}$ are compared to reference data $x_{i}$ by using the following statistical indexes: relative bias (units of \%), relative root-mean square error (RMS, units of \%) and determination coefficient $\left(r^{2}\right)$

$$
\begin{gathered}
\text { bias }=100 \frac{1}{N} \sum_{i=1}^{N} \frac{y_{i}-x_{i}}{x_{i}} \\
R M S=100 \sqrt{\frac{1}{N} \sum_{i=1}^{N}\left(\frac{y_{i}-x_{i}}{x_{i}}\right)^{2}} \\
r^{2}=\frac{\sum_{i=1}^{N}\left(x_{i}-\bar{x}\right)\left(y_{i}-\bar{y}\right)}{\sqrt{\sum_{i=1}^{N}\left(x_{i}-\bar{x}\right)^{2}} \sqrt{\sum_{i=1}^{N}\left(y_{i}-\bar{y}\right)^{2}}}
\end{gathered}
$$

\subsection{In Situ Data}

The in situ database is composed of three distinct datasets containing multi-spectral $R_{\mathrm{rs}}$ and $\mathrm{b}_{\mathrm{bp}}$ : the recently updated global in situ database ([33] hereafter V19 dataset), an in situ dataset collected by the Italian National Research Council (CNR) during two field campaigns in the Mediterranean Sea ([29] hereafter CNR dataset) and the time-series of data acquired by the BOUSSOLE buoy in the northwestern Mediterranean Sea ([34,41]; hereafter BOU dataset [42]). The three in situ databases were quality-checked as described below. All the $\mathrm{R}_{\mathrm{rs}}$ data were band-shifted to the CCI bands (those of the NASA SeaWiFS instrument, namely 412, 443, 490, 510, 555, and $670 \mathrm{~nm}$ ). The band-shifting procedure [43] is a technique to compensate small band differences in multispectral $R_{r s}$ data. It takes into account the spectral shape of the absorption and scattering that contribute to $\mathrm{R}_{\mathrm{rs}}$ and constitutes a more accurate approach than a simple linear interpolation. Considering every wavelength an independent measurement, the final dataset accounts for a total of $N=2881 \mathrm{R}_{\mathrm{rs}}$ and $\mathrm{b}_{\mathrm{bp}}$ co-located measurements around the global ocean (Figure 1). As shown in Figure 2, the total $R_{r s}$ and $b_{b p}$ spectra cover from oligotrophic open-ocean to more eutrophic coastal waters as the range of $R_{r s}$ and $b_{b p}$ values vary between $0-0.02 \mathrm{sr}^{-1}$ and $10^{-4}-10^{-1} \mathrm{~m}^{-1}$ respectively. 


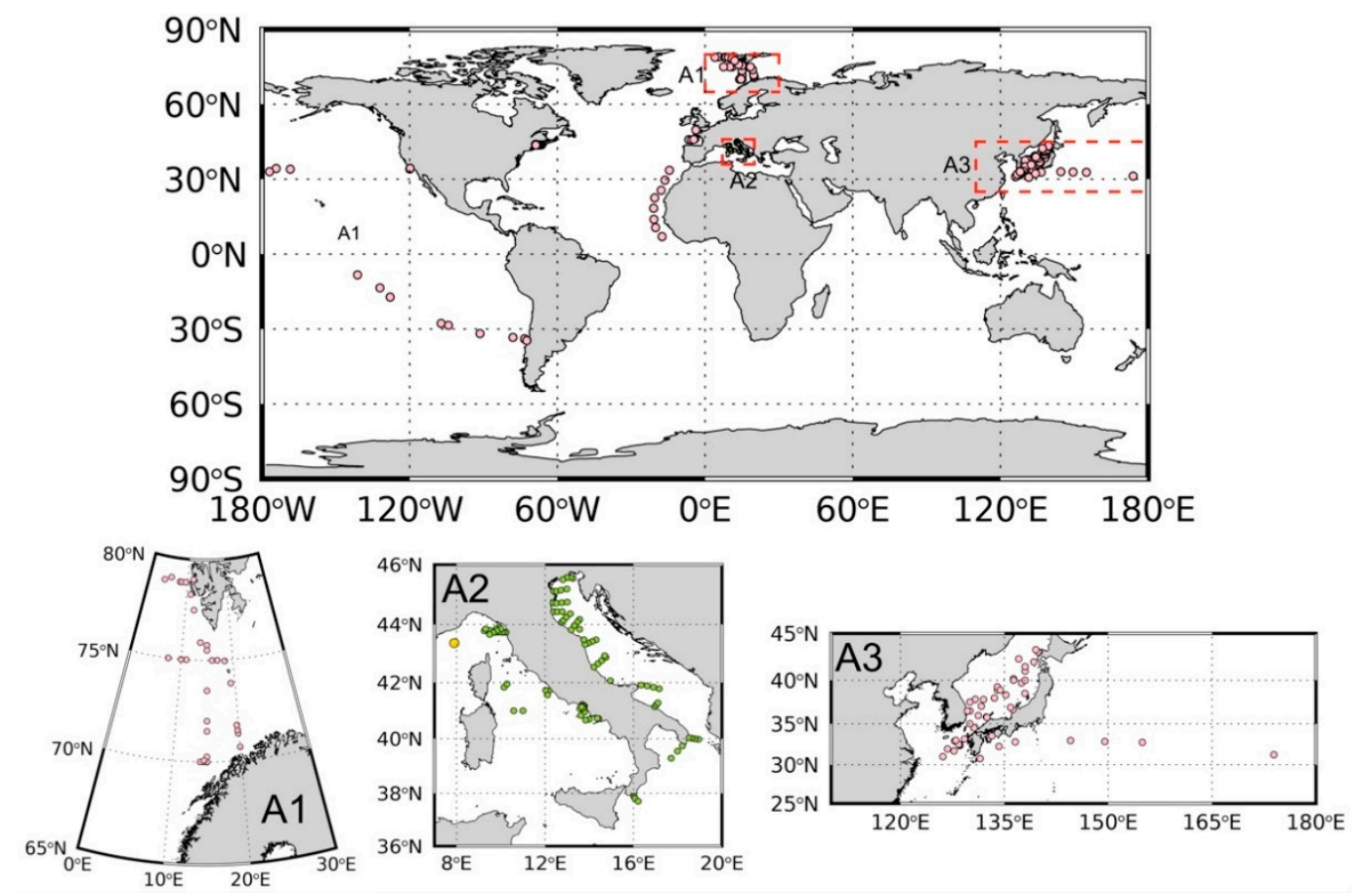

Figure 1. Geographical distribution of the in situ $R_{r s}$ vs. $b_{b p}$ matchups. Some areas (A1, A2, and A3) concentrate a high point density and are highlighted in zoomed maps. Pink, yellow, and green dots refer to V19, BOU, and CNR data, respectively.
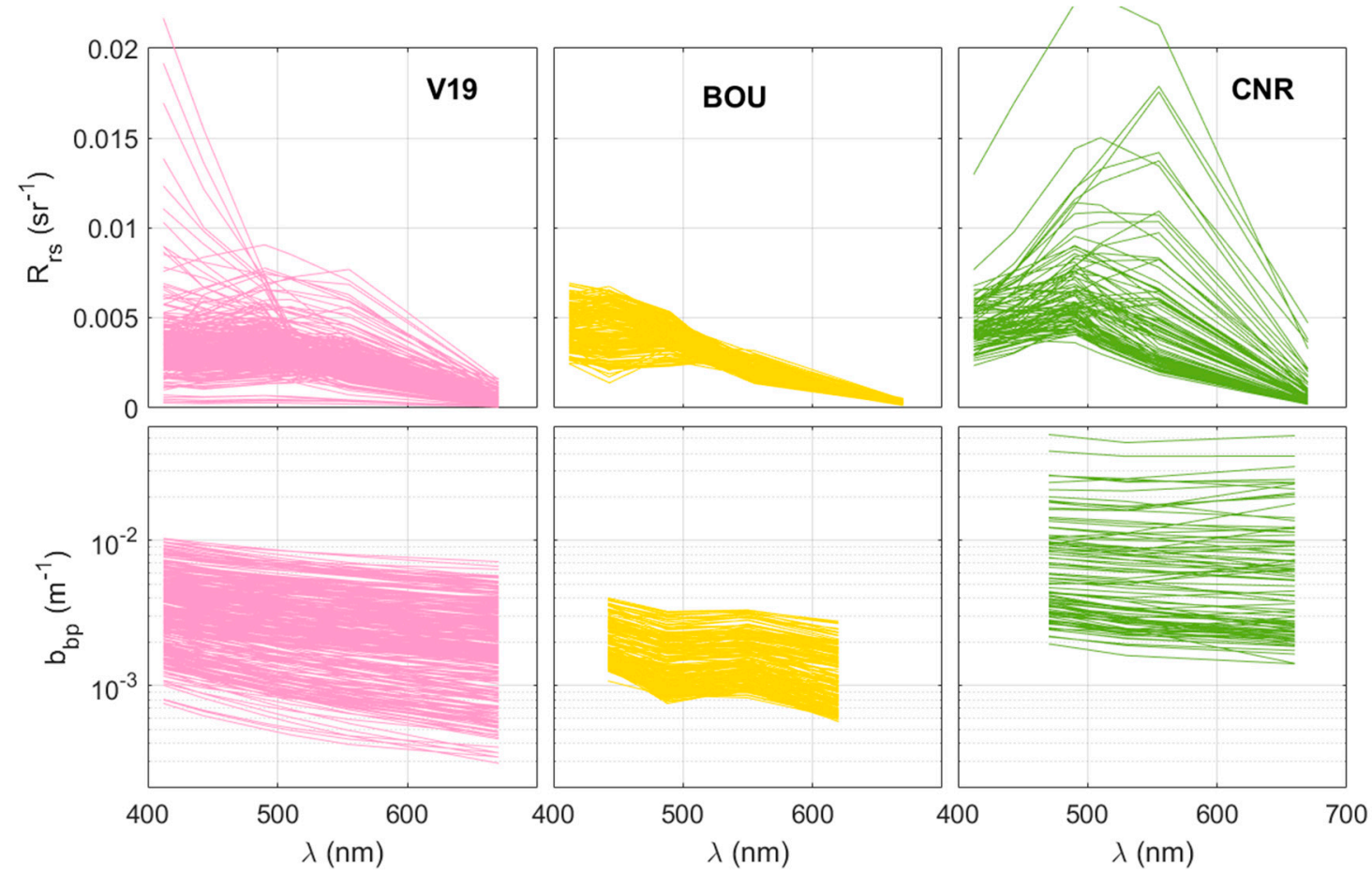

Figure 2. $R_{r s}$ and $b_{b p}$ spectra for the three-different datasets: V19, BOU, and CNR. Pink, yellow, and green lines refer to V19, BOU, and CNR data, respectively.

\subsubsection{V19 Dataset}

$\mathrm{R}_{\mathrm{rs}}$ and IOPs, aggregated within $\pm 6 \mathrm{~nm}$, were downloaded. V19 is a global compilation of in situ data that was acquired from many sources (e.g., MOBY, AERONET-OC, SeaBASS, NOMAD, MERMAID, AMT, and many others), motivated by the validation of the ocean-color products from the 
ESA OC-CCI products. Methodologies were implemented for homogenization, quality control and merging of all data. No changes were made to the original data, other than averaging of observations that were close in time and space, elimination of some points after quality control and conversion to a standard format [44].

In this study, data were selected only if valid and corresponding $R_{r s}$ and $b_{b p}$ measurements at all CCI bands were available. Such condition determines a total of $N=319$ matchups. Remaining minor $b_{b p}$ wavelength mismatches were removed by linear interpolation to the CCI bands. Although V19 is a merged dataset from multiple datasets, the condition we set for the matchup left data that were originally from the NOMAD dataset only.

\subsubsection{BOU Dataset}

The BOUSSOLE (BOUee pour l'acquiSition d'une Série Optique a Long termE) project started in 1999, and its activities are developed on a site located in the northwestern Mediterranean Sea $\left(7^{\circ} 54^{\prime} \mathrm{E}\right.$, $43^{\circ} 22^{\prime} \mathrm{N}$, Figure 1, panel A2). Essential information about the site characteristics, the measurement platform, and the instrumentation was previously documented [34,41,42]. The $b_{\mathrm{bp}}$ data were collected at $9 \mathrm{~m}$ nominal depth with a Hobilabs Hydroscat-4 $(442,488,550$, and $620 \mathrm{~nm})$ and processed as in [45]. In addition, a quality control on $b_{\mathrm{bp}}$ was applied that required a spectral $b_{\mathrm{bp}}$ slope, calculated from every pair of two consecutive bands, within given bounds (more than -1 and less than 6). $R_{\mathrm{rs}}$ data were derived with a set of Satlantic 200-series multispectral radiometers ([46] and references therein). The $\mathrm{R}_{\mathrm{rs}}$ is available at a varying number of the following bands, depending on the time period: 412.5, $442.5,490,510,555,560,665,670$, and $681.25 \mathrm{~nm}$. Since the application of the QAA requires $\mathrm{R}_{\mathrm{rs}}$ at $443,490,555$, and $670 \mathrm{~nm}$, only $\mathrm{R}_{\mathrm{rs}}$ records whose native bands matched those needed by the QAA algorithms were selected (within a $\pm 6 \mathrm{~nm}$ range). Data at $412.5 \mathrm{~nm}$ and $442.5 \mathrm{~nm}$ were band-shifted to $412 \mathrm{~nm}$ and $443 \mathrm{~nm}$ [43], respectively. In the green region, if the $R_{\mathrm{rs}}$ at $555 \mathrm{~nm}$ was available, it was directly sampled and the $R_{r s}$ at $560 \mathrm{~nm}$ was ignored. If the $R_{r s}$ at $560 \mathrm{~nm}$ was available when the $R_{r s}$ at $555 \mathrm{~nm}$ was missing, the $R_{\mathrm{rs}}$ at $560 \mathrm{~nm}$ was band-shifted to $555 \mathrm{~nm}$. Similarly, in the red region, between the $R_{r s}$ at $665 \mathrm{~nm}$ and $670 \mathrm{~nm}$, preference to $R_{r s}$ at $670 \mathrm{~nm}$ was given. $R_{r s}$ data at $681.25 \mathrm{~nm}$ was not considered for the analysis. Data was generally available within two hours from the local noon. The time series at sub-daily resolution were reduced by calculating the daily medians.

\subsubsection{CNR Dataset}

Data belong to two field campaigns conducted in 2013 and 2015 in Italian seas, encompassing a high optical range between open and coastal waters. Measurements were performed between 8:30 $\mathrm{h}$ and 16:00 $\mathrm{h}$ UTC. IOPs and $\mathrm{R}_{\mathrm{rs}}$ were collected sequentially at each station, with a maximum delay of $\sim 1 \mathrm{~h}$ and ship drift of maximum few hundreds of meters.

Backscattering was measured with an ECO-VSF3, manufactured by WET Labs, Inc., at the wavelengths 470,530, and $660 \mathrm{~nm}$. This instrument measures the volume scattering function at three backward angles and calculates $b_{b}$ by integration of a polynomial fit. Final data are the result of $a$ binning across the first optical depth.

Radiometry was performed with OCR-507 radiometers, manufactured by Satlantic, Inc., measuring at the center bands $412,443,490,510,556,665$, and $865 \mathrm{~nm}$. In-water upwelling radiance at nadir $\left(\mathrm{L}_{\mathrm{u}}\right)$ sensor was mounted onto a free-falling T-shaped structure, with the multicast technique. Above-water downwelling irradiance $\left(E_{s}\right)$ data were collected by a reference sensor, mounted at the top of the ship's deck. $R_{\mathrm{rs}}$ was computed using the SERDA software developed at CNR [47]. All the $\mathrm{R}_{\mathrm{rs}}$ data were band-shifted to the CCI bands for consistency with the satellite $\mathrm{R}_{\mathrm{rs}}$. Further details about this dataset are provided in Pitarch et al. [29].

\subsection{Satellite ESA OC-CCI $R_{r s}$ Data}

The ESA OC-CCI version 4.0 global daily $R_{\mathrm{rs}}$ data at $4 \mathrm{~km}$ resolution for the period 1997-2017 were downloaded [48]. CCI products are the result of the merging of SeaWiFS, MERIS, MODIS, and VIIRS 
data in which the inter-sensor biases are removed [49]. This version 4.0 includes the latest NASA reprocessing R2018.0 that mostly accounts for the aging of the MODIS sensor. ESA OC-CCI provides the daily $R_{r s}$ data and associated uncertainty maps in terms of bias and RMS, which were generated with a procedure that included comparison to in situ data and optical water type analysis [48].

In this work, a conservative extraction procedure was followed, in which the center $R_{\mathrm{rs}}$ data within a $3 \times 3$ pixels box was extracted only if all the 9 pixels were not flagged, therefore minimizing possible land border, cloud or other environmental contaminations, and obtaining the highest quality of matchups. Finally, for each single $\mathrm{R}_{\mathrm{rs}}$, the bias was also extracted and then compensated pixel-by-pixel.

\section{Results and Discussion}

\subsection{QAA Performance for $b_{b p}$ Retrievals from In Situ Data}

QAA-retrieved $b_{b p}$ from in situ $R_{r s}$ is here compared to in situ measured $b_{b p}$. Comparisons are made at the native bands of each in situ $b_{b p}$ instrument for the cases of BOU and CNR and at the CCI bands for V19. Statistics are also presented for each band and dataset.

A first assessment consists of applying the QAA without performing the compensation for Raman scattering. Here, results show a general overestimation of around $+43.4 \%$ for V19 (Table 1 ) that is not significant given the overall noise expressed by the RMS (152\%). This high RMS is the likely consequence of the different protocols, instrumental and geophysical noises affecting all single contributors to the V19 dataset (Table 1). In the case of the BOU dataset, an overall overestimation of $+49.2 \%$ is found for all the bands which is statistically significant given the related RMS (58.7\%). On the other hand, the QAA applied to the CNR dataset showed the highest performances, with a bias of $+3.3 \%$ and a RMS below $23 \%$.

Table 1. Statistical descriptors of the difference between the QAA-derived $b_{b p}$ and in situ $b_{b p}$ for each dataset, without Raman scattering compensation. Figure A1 provides a graphical representation of this table.

\begin{tabular}{cccccc}
\hline & Band (nm) & Bias (\%) & RMS (\%) & $\mathbf{r}^{\mathbf{2}}$ & $\mathbf{N}$ \\
\hline \multirow{6}{*}{ V19 } & 412 & 40.3 & 128.4 & 0.35 & 319 \\
& 443 & 42.7 & 129.4 & 0.37 & 319 \\
& 490 & 44.5 & 127.8 & 0.41 & 319 \\
& 510 & 45.0 & 127.1 & 0.42 & 319 \\
& 555 & 45.2 & 124.2 & 0.44 & 319 \\
& 670 & 43.1 & 114.2 & 0.47 & 319 \\
BOU & All & 43.4 & 125.3 & 0.43 & 1914 \\
\hline \multirow{6}{*}{ CNR } & 442 & 44.5 & 50.7 & 0.73 & 172 \\
& 488 & 71.3 & 79.2 & 0.73 & 172 \\
& 550 & 29.0 & 36.5 & 0.78 & 172 \\
& 620 & 52.0 & 60.2 & 0.73 & 172 \\
& All & 49.2 & 58.7 & 0.75 & 688 \\
\hline & 470 & 11.8 & 25.1 & 0.88 & 93 \\
& 530 & 7.7 & 22.8 & 0.89 & 93 \\
& 660 & -9.6 & 20.7 & 0.93 & 93 \\
& All & 3.3 & 22.9 & 0.88 & 279 \\
\hline
\end{tabular}

To understand the importance of the Raman scattering correction in semi-analytical $b_{\mathrm{bp}}$ retrievals, the analysis is repeated with corrected $R_{r s}$ [40]. The application of the Raman scattering correction reduces both bias and RMS nearly for all the $b_{b p}$ at all bands (Table 2 and Figure 3 ). Indeed, for the V19 dataset, the bias decreases to $12 \%$ with respect to the retrievals obtained without correction of the Raman scattering (Table 2). The RMS reduction is around 34\%. For the BOU data, the RMS and bias improve of about $11 \%$ and $12 \%$, respectively. In the case of the CNR dataset, statistics show a modest increase in accuracy except for $\lambda=660 \mathrm{~nm}$, which is likely influenced by chlorophyll-a fluorescence. 
Although fluorescence peaks at around $\lambda=660 \mathrm{~nm}$, the ECO-VSF 3 sensor, used to collect the CNR dataset, has a full width at half maximum (FWHM) of about 20 to $30 \mathrm{~nm}$, so a fluorescence interference may not be excluded.

Overall, these results are somewhat expected as the Raman scattering correction produces a smaller effect in coastal waters [50], which represent a significant part of the CNR dataset with respect to the two other datasets (Figure 2). The overall statistics are in agreement with previous comparisons that showed negligible biases over noise at global scale [5] and at regional level [29]. Results in this section highlight the importance of applying the Raman scattering correction to the source $\mathrm{R}_{\mathrm{rs}}$ prior to semi-analytical $b_{b p}$ retrieval in order to increase the accuracy.

Table 2. Statistical descriptors of the difference between the $b_{b p}$-QAA derived and in situ $b_{b p}$ for each dataset with Raman scattering compensation. Figure A2 provides a graphical representation of this table.

\begin{tabular}{cccccc}
\hline & Band (nm) & Bias (\%) & RMS (\%) & $\mathbf{r}^{\mathbf{2}}$ & $\mathbf{N}$ \\
\hline \multirow{6}{*}{ V19 } & 412 & 28.5 & 94.6 & 0.45 & 319 \\
& 443 & 30.7 & 95.0 & 0.47 & 319 \\
& 490 & 32.2 & 93.4 & 0.50 & 319 \\
& 510 & 32.6 & 92.8 & 0.51 & 319 \\
& 555 & 32.7 & 90.4 & 0.52 & 319 \\
& 670 & 30.7 & 83.1 & 0.54 & 319 \\
BOU & All & 31.2 & 91.6 & 0.52 & 1914 \\
\hline \multirow{6}{*}{ CNR } & 442 & 33.0 & 40.1 & 0.73 & 172 \\
& 488 & 57.2 & 64.8 & 0.73 & 172 \\
& 550 & 18.2 & 27.1 & 0.78 & 172 \\
& 620 & 39.0 & 47.8 & 0.73 & 172 \\
& All & 37.0 & 47.0 & 0.75 & 688 \\
\hline & 470 & 6.5 & 22.6 & 0.88 & 93 \\
& 530 & 2.5 & 21.3 & 0.89 & 93 \\
& 660 & -14.2 & 23.0 & 0.93 & 93 \\
& All & -1.73 & 22.3 & 0.89 & 279 \\
\hline
\end{tabular}

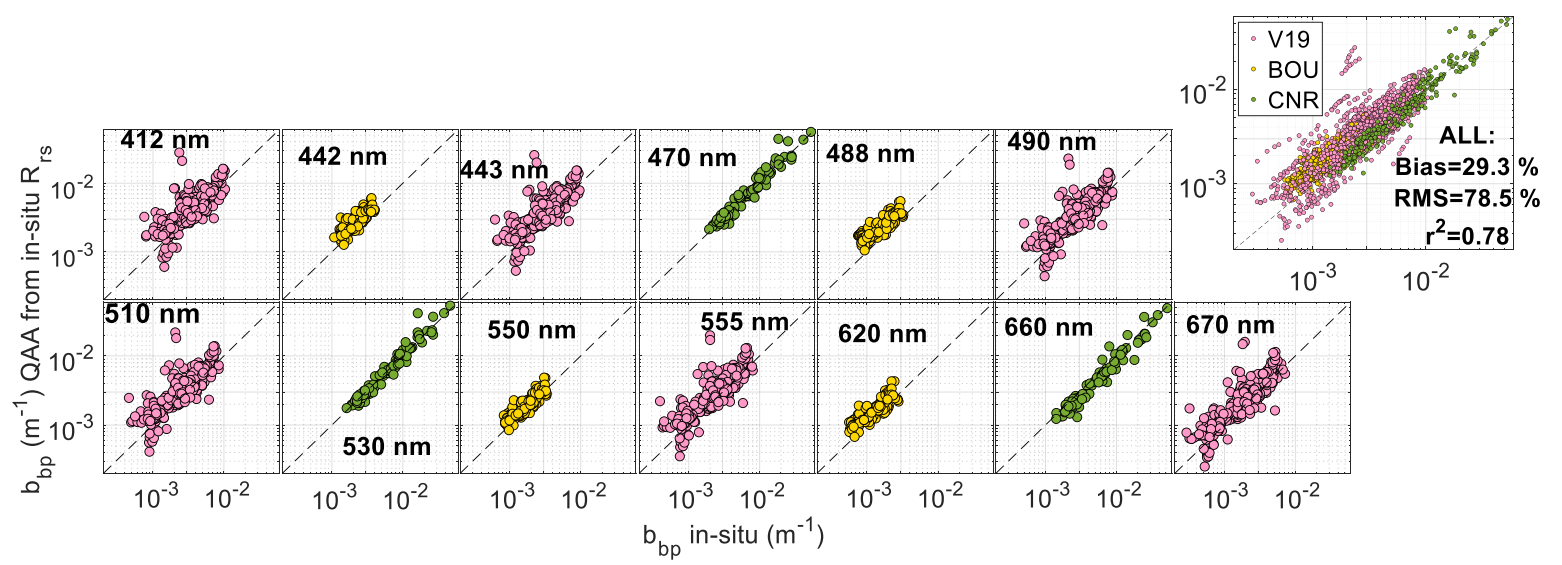

Figure 3. Scatter plots of QAA-derived $b_{b p}$ vs. in situ $b_{b p}$ data for each wavelength and dataset considered and for the merged dataset. Raman correction is applied to $\mathrm{R}_{\mathrm{rs}}$. The dashed line represents the 1:1 ratio. Pink, yellow and green dots refer to V19, BOU and CNR data, respectively.

\subsection{Estimation of the $b_{b p}$ Spectral Slope from $R_{r s}$ Data}

The in situ dataset described above is used (see Section 2.2) to assess the proposed relationship in the QAA and perform a model to data fit that is compared to the common QAA v6 equation [50]. Figure 4 shows a comparison of the independent variable (i.e., the blue-to-green band ratio $\mathrm{r}_{\mathrm{rs}}(443) / \mathrm{r}_{\mathrm{rs}}(555)$ ) 
with respect to $\eta$ derived from the in situ $b_{b p}$. Fitting a functional form of Equation (1) returns a curve $\left(\mathrm{p}_{1}=2.2, \mathrm{p}_{2}=0.9\right.$ and $\left.\mathrm{p}_{3}=0.5\right)$ and a $95 \%$ prediction interval, which is around \pm 1 wide, caused by the high scatter of the data cloud. The difference between $\eta$ computed here and the one derived via QAA is much smaller than the width of the prediction interval, thus making them equivalent for prediction purposes. Therefore, by the principle of parsimony, the operational $\eta$ functional form (dashed line in Figure 4) remains valid. However, one must keep in mind that the low predictive value of this relationship may result in $b_{\mathrm{bp}}$ extrapolations to bands outside the reference one (usually $555 \mathrm{~nm}$ ) that accumulate significant errors. In particular, within a worst-case scenario, an error in $\eta$ estimation, $\Delta \eta=1$, will lead to a $\sim 26 \%$ error when extrapolating $b_{\mathrm{bp}}$ from $555 \mathrm{~nm}$ to $412 \mathrm{~nm}$.

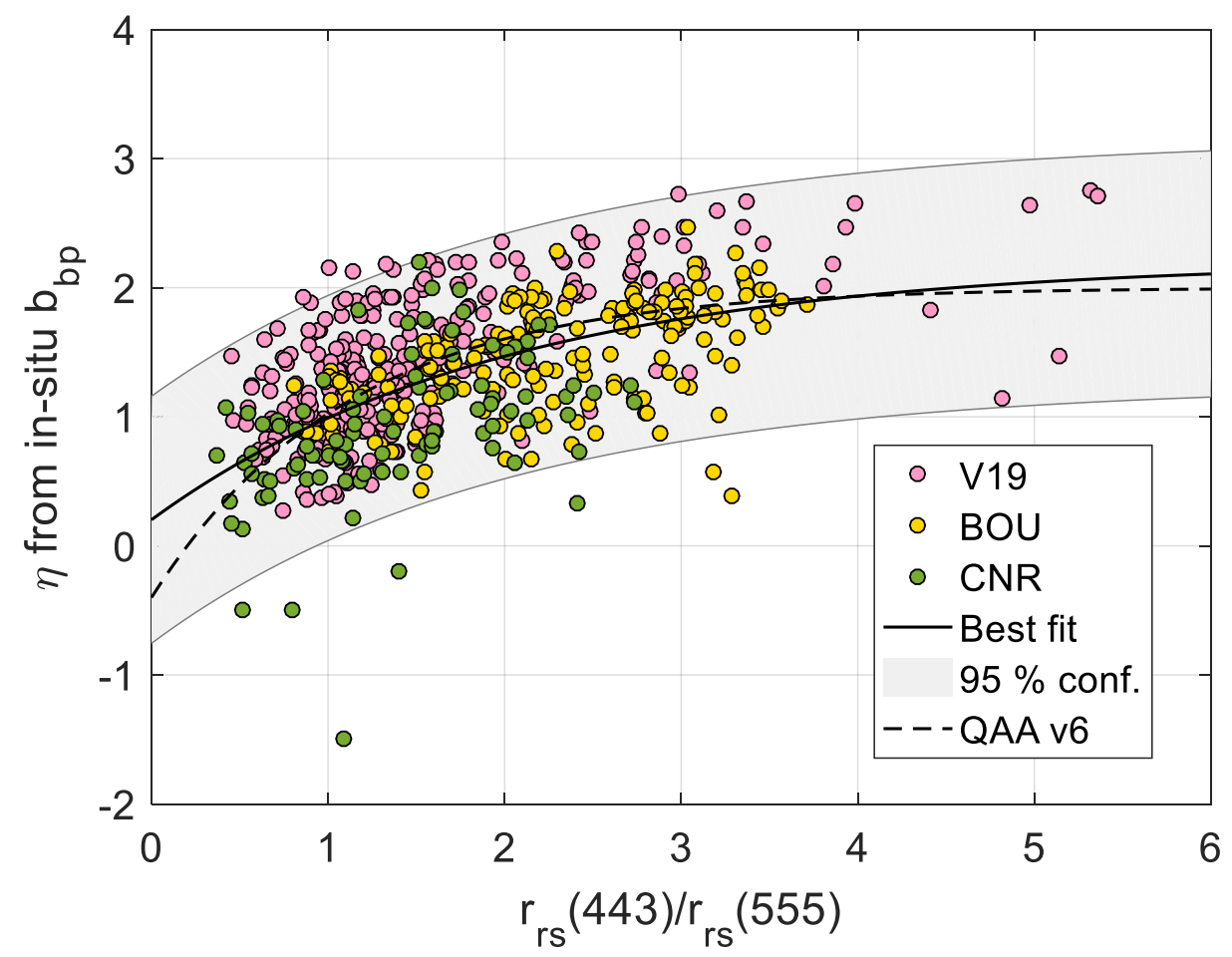

Figure 4. $\eta$ calculation considering all the in situ data available: V19 (pink dots), BOU (yellow dots), and CNR (green dots). The solid curve is the best fit of Equation (1) to all the data ( $\mathrm{p}_{1}=2.2, \mathrm{p}_{2}=0.9$ and $\left.p_{3}=0.5\right)$. The $95 \%$ confidence prediction bounds are represented by the grey shaded area. The dashed curve is the $\eta$ estimation from $\mathrm{R}_{\mathrm{rs}}$ as defined in Equation (1). Pink, yellow, and green dots refer to V19, $\mathrm{BOU}$, and $\mathrm{CNR}$ data, respectively.

\subsection{Validation of CCI $R_{r s}$}

Prior to applying to satellite data an algorithm that has been developed with in situ data, assessing the quality of the satellite $R_{\mathrm{rs}}$ with respect to in situ measured $R_{\mathrm{rs}}$ is desirable in order to identify possible biases. Therefore, this section uses the in situ $R_{r s}$ contained in the three datasets to evaluate the CCI R $R_{r s}$. There is a total of 882 matchups for V19, 581 for BOU, and 252 for CNR. Good agreement between in situ values and the CCI $R_{\mathrm{rs}}$ products is found (Figure 5, Table 3) at all wavelengths, rather consistently with other previous results [5]. Overall, all datasets display similar performance, with negligible biases with respect to the overall noise expressed by the RMS. In the case of $\lambda=670$, increased RMS is mostly due to the low values $R_{r s}$, except for $C N R$, that contains a higher data range. It is concluded that the CCI $R_{r s}$ do not require adjustments at the studied wavelengths.

The magnitude of this RMS expresses a high bound for the overall uncertainty of the $\mathrm{R}_{\mathrm{rs}}$ product as it is a measure of the errors in the comparison experiment, including those within the in situ data. The fraction of this error which is attributable to the satellite data only is likely to be much lower. 
To have a measure of this fraction, a comparison to global in situ dataset with a traceable uncertainty budget would be desirable, though such option is presently not available.

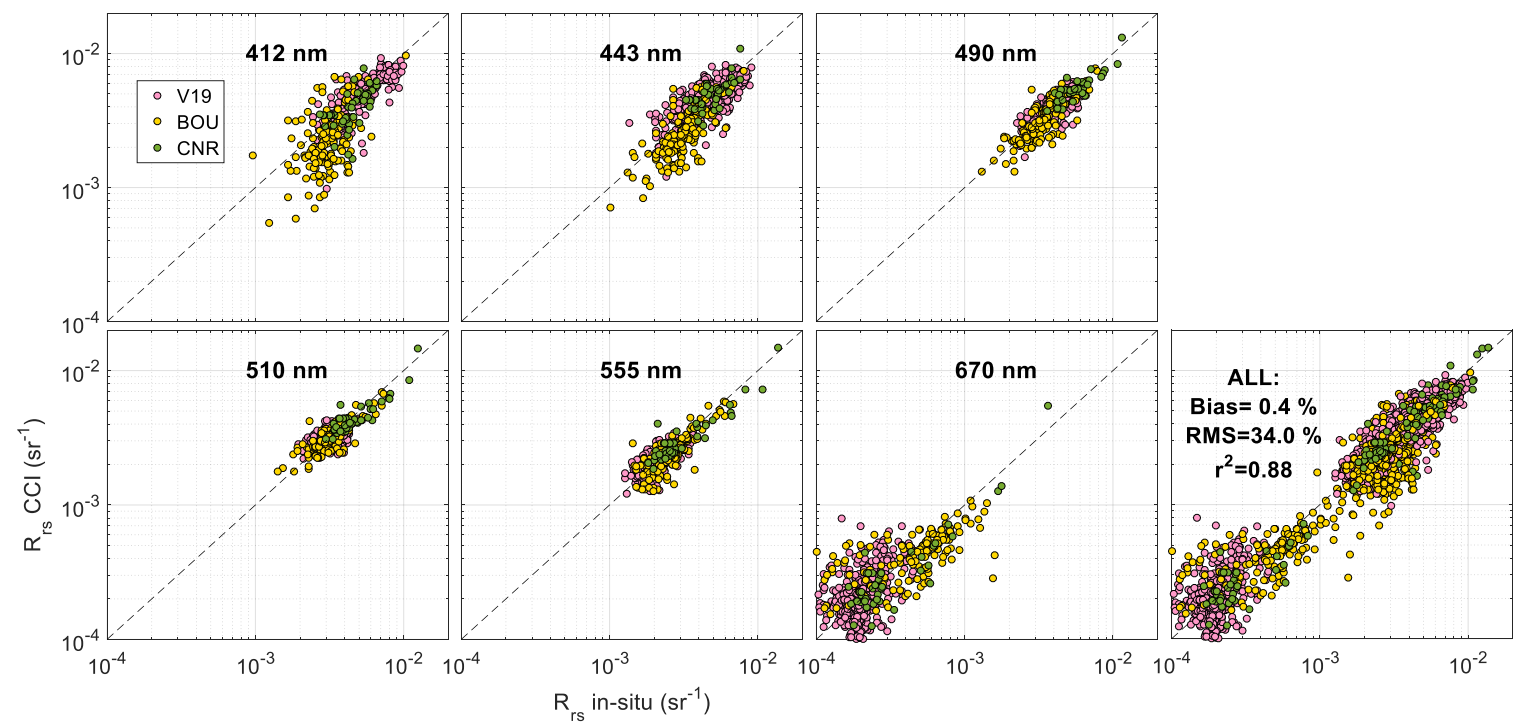

Figure 5. Scatter plots of CCI $R_{r s}$ versus in situ $R_{r s}$ for the six different wavelengths. The dashed line represents the 1:1 ratio. Pink, yellow, and green dots refer to V19, BOU, and CNR data, respectively.

Table 3. Statistical descriptors of the difference between satellite CCI $R_{r s}$ and in situ $R_{r s}$ for each dataset. Figure A3 provides a graphical representation of this table.

\begin{tabular}{cccccc}
\hline & Band (nm) & Bias (\%) & RMS (\%) & $\mathbf{r}^{2}$ & $\mathbf{N}$ \\
\hline \multirow{6}{*}{ V19 } & 412 & -19.6 & 42.7 & 0.37 & 147 \\
& 443 & -16.9 & 30.6 & 0.53 & 147 \\
& 490 & -5.0 & 19.3 & 0.66 & 147 \\
& 510 & -0.4 & 15.3 & 0.73 & 147 \\
& 555 & -4.6 & 18.7 & 0.78 & 147 \\
& 670 & 28.4 & 117.9 & 0.47 & 147 \\
All & -3.0 & 54.2 & 0.73 & 882 \\
\hline \multirow{6}{*}{ BOU } & 412 & -4.0 & 22.5 & 0.50 & 96 \\
& 443 & -3.7 & 23.9 & 0.63 & 97 \\
& 490 & -1.9 & 11.1 & 0.66 & 97 \\
& 510 & -6.4 & 11.9 & 0.47 & 97 \\
& 555 & 9.5 & 16.0 & 0.64 & 97 \\
& 670 & 24.2 & 49.5 & 0.31 & 97 \\
All & 3.0 & 26.0 & 0.89 & 581 \\
\hline \multirow{6}{*}{ ANR } & 412 & -10.7 & 24.8 & 0.42 & 42 \\
& 443 & 2.6 & 18.2 & 0.53 & 42 \\
& 490 & -0.4 & 13.2 & 0.75 & 42 \\
& 510 & -3.7 & 14.9 & 0.81 & 42 \\
& 555 & 0.9 & 19.9 & 0.88 & 42 \\
& 670 & -4.9 & 83.1 & 0.90 & 42 \\
& All & -2.7 & 21.9 & 0.87 & 252 \\
\hline
\end{tabular}

\subsection{QAA Performance for $b_{b p}$ Retrievals from CCI Data}

After assessing the quality of the QAA retrievals with in situ $b_{\mathrm{bp}}$ and the quality of the CCI $\mathrm{R}_{\mathrm{rs}}$ respect to in situ $R_{r s}$, the QAA is applied to the CCI $R_{r s}$ to retrieve the $b_{b p}$ that are then compared to the in situ data. In agreement with our findings in Section 3.1, CCI $R_{\mathrm{rs}}$ are corrected for Raman scattering. Results of this comparison are shown in Figure 6 and Table 4. For V19, biases are not significant (less than $30 \%$ ) in comparison of RMS values (less than $60 \%$ ). On the other hand, similarly to the statistics 
derived from Section 3.1, QAA-derived $b_{\mathrm{bp}}$, as compared to the BOU data displays significant positive biases. Comparison with CNR data shows the highest performances, with bias of $+2.7 \%$ and RMS of $48 \%$. The conclusions from our analysis are consistent with previous comparisons to QAA, reporting negligible biases above noise level both at global and regional scales $[25,30,51]$.

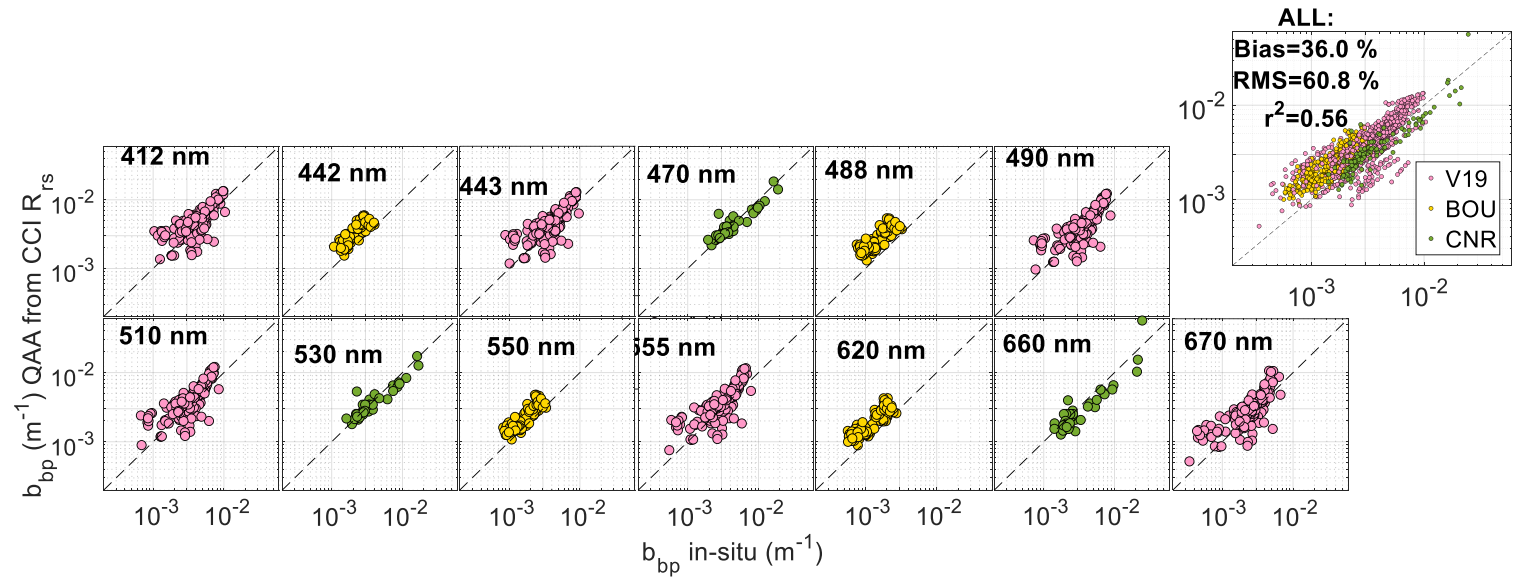

Figure 6. Scatter plots of QAA derived $b_{b p}$ from CCI $R_{r s}$ versus in situ $b_{b p}$ data for each wavelength and dataset considered and for the merged data set. The dashed line represents the 1:1 ratio. Pink, yellow, and green dots refer to V19, BOU, and CNR data, respectively.

Table 4. Statistical descriptors of the difference between the QAA-derived $b_{b p}$ from satellite CCI $R_{r s}$ and in situ $b_{\mathrm{bp}}$ for each dataset with Raman scattering compensation. Figure A4 provides a graphical representation of this table.

\begin{tabular}{cccccc}
\hline & Band (nm) & Bias (\%) & RMS (\%) & $\mathbf{r}^{\mathbf{2}}$ & $\mathbf{N}$ \\
\hline \multirow{6}{*}{ V19 } & 412 & 24.2 & 51.8 & 0.66 & 147 \\
& 443 & 26.8 & 53.9 & 0.67 & 147 \\
& 490 & 29.1 & 56.0 & 0.68 & 147 \\
& 510 & 29.9 & 56.8 & 0.67 & 147 \\
& 555 & 31.0 & 58.1 & 0.67 & 147 \\
& 670 & 31.6 & 60.7 & 0.62 & 147 \\
BOU & All & 28.8 & 56.3 & 0.68 & 882 \\
\hline \multirow{6}{*}{ CNR } & 442 & 56.6 & 62.7 & 0.67 & 97 \\
& 488 & 86.9 & 96.2 & 0.64 & 97 \\
& 550 & 41.9 & 50.2 & 0.70 & 97 \\
& 620 & 66.8 & 75.3 & 0.69 & 97 \\
& All & 63.1 & 73.1 & 0.69 & 388 \\
\hline & 470 & 10.1 & 52.9 & 0.48 & 42 \\
& 530 & 7.8 & 54.9 & 0.46 & 42 \\
& 660 & -9.6 & 33.5 & 0.63 & 42 \\
& All & 2.7 & 48.1 & 0.50 & 126 \\
\hline
\end{tabular}

\section{Conclusions}

The main findings of this work and their relevance for ocean color studies are summarized here:

(1) Raman scattering compensation of $\mathrm{R}_{\mathrm{rs}}$ prior to the application of the QAA significantly reduces errors in the retrieval of $b_{b p}$ with respect to in situ $b_{b p}$. Inclusion of this processing step in operational schemes is recommended.

(2) The QAA-derived $b_{b p}$ from in situ radiometry has negligible biases with respect to in situ $b_{b p}$.

(3) CCI R $\mathrm{r}_{\mathrm{rs}}$ shows low biases but higher RMS differences with respect to in situ data, that could be excessive for the monitoring of natural change over short periods. Here, the standardization of in 
situ radiometry protocols is highly encouraged [52], in order to reduce the errors when in situ datasets formed by multiple contributors are merged and used for $\mathrm{R}_{\mathrm{rs}}$ matchup analysis.

(4) In part as a consequence of the findings above, QAA-derived $b_{b p}$ from CCI $R_{r s}$ displays negligible biases respect to in situ $b_{\mathrm{bp}}$, with moderately low RMS errors.

(5) The in situ radiometry-derived spectral backscattering slope $(\eta)$ has low predictive value as compared to $\eta$ derived from $b_{b p}$ matchups. In this context, the impact of using the best fitted curve instead of the widely used expression [22] is negligible, thus validating the application of the latter without its retuning.

Notwithstanding these results, one future challenge should be to evaluate the impact of two other sources of inelastic scattering before the application of QAA on $\mathrm{R}_{\mathrm{rs}}$ : (i) red fluorescence, caused by chlorophyll, that usually plays an important role around the peak close to $685 \mathrm{~nm}$; and (ii) the blue fluorescence, caused by CDOM, that can be relevant close to the peak at $425 \mathrm{~nm}$ [53].

In addition, there is the need of increasing the amount of spatial and spectral coverage of high-quality in situ $b_{\mathrm{bp}}$ observations. As of today, available multispectral $b_{\mathrm{bp}}$ is limited to a small number of ship-borne data, or longer datasets but in fixed points (i.e., buoy). On the other hand, Biogeochemical-Argo floats cover large areas but their data are mainly given at a single band. Therefore, there is need to significantly increase the amount of $b_{\mathrm{bp}}$ data at multiple bands, seasons and geographical regions. New technological developments on autonomous platforms will aid to enhance data density across many water types, to extend the $\mathrm{CCI}$ uncertainty derivation approach to $b_{\mathrm{bp}}$ as well, thus allowing the mapping of uncertainties for every $b_{b p}$ product.

Lastly, in situ $b_{b p}$ measurements lag behind the standards on protocols and uncertainty characterization with respect to other quantities such as the radiometry [52]. Only when in situ uncertainty-characterized datasets, from instrument characterization to deployment [54], become available, more detailed algorithm validation could be performed and this will help to better evaluate the influence of optically active constituents (e.g., CDOM, chlorophyll).

Author Contributions: Conceptualization, J.P., M.B., and S.M.; Methodology, J.P., M.B., and S.M.; Data curation, J.P., E.O., G.V., S.C., V.V.; Writing-review and editing, all authors contributed equally. All authors have read and agreed to the published version of the manuscript.

Funding: J.P. has received partial funding from the 'Coastal Ocean Darkening' project funded by the Ministry for Science and Culture of Lower Saxony, Germany (VWZN3175). M.B. has a postdoctoral fellowship by the European Space Agency (ESA). This work was supported by the ESA Living Planet Fellowship Project PHYSIOGLOB: Assessing the inter-annual physiological response of phytoplankton to global warming using long-term satellite observations, 2018-2020.

Acknowledgments: This is a contribution to the ESA Ocean Colour Climate Change Initiative of the European Space Agency. ESA and CNES are thanked for funding the BOUSSOLE project. We are grateful to all the contributors to the V19 dataset. J.P. thanks CNR-ISMAR for the stay at the Rome CNR location in which this manuscript was elaborated. Finally, we wish to thank four anonymous reviewers for their criticisms and suggestions that helped the manuscript to be improved.

Conflicts of Interest: The authors declare no conflict of interest.

\section{Appendix A}

This appendix includes the graphical representation of the information in Tables 1-4, for a quicker interpretation of the results and the derived conclusions. The error bars are made by taking the mean bias in tables as central values and the standard deviation $(\sigma)$ as bar width, calculated as $\sigma=\sqrt{\text { RMS }^{2}-\text { Bias }^{2}}$. When error bars intersect the zero-difference line, the differences are assumed to be not significant. 


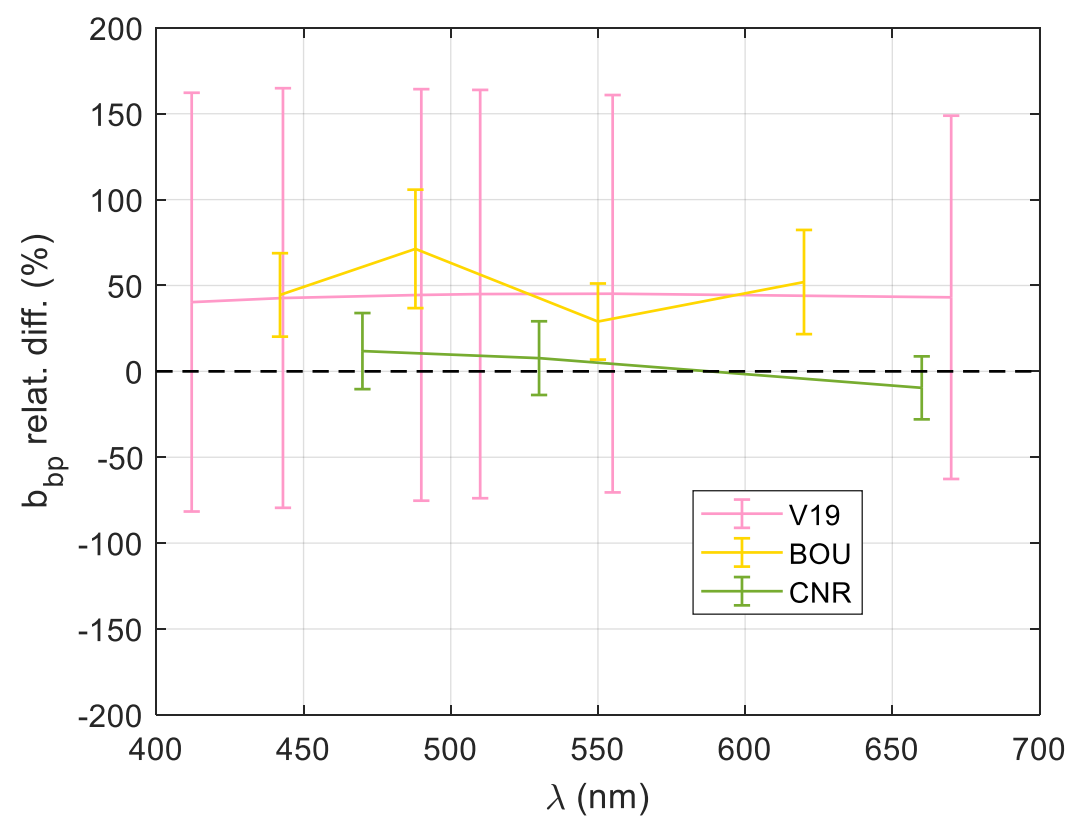

Figure A1. Relative differences between the QAA-derived $b_{\mathrm{bp}}$ and in situ $b_{\mathrm{bp}}$ for each dataset, without Raman scattering compensation. Data taken from Table 1. Pink, yellow, and green lines refer to V19, BOU, and CNR data, respectively.

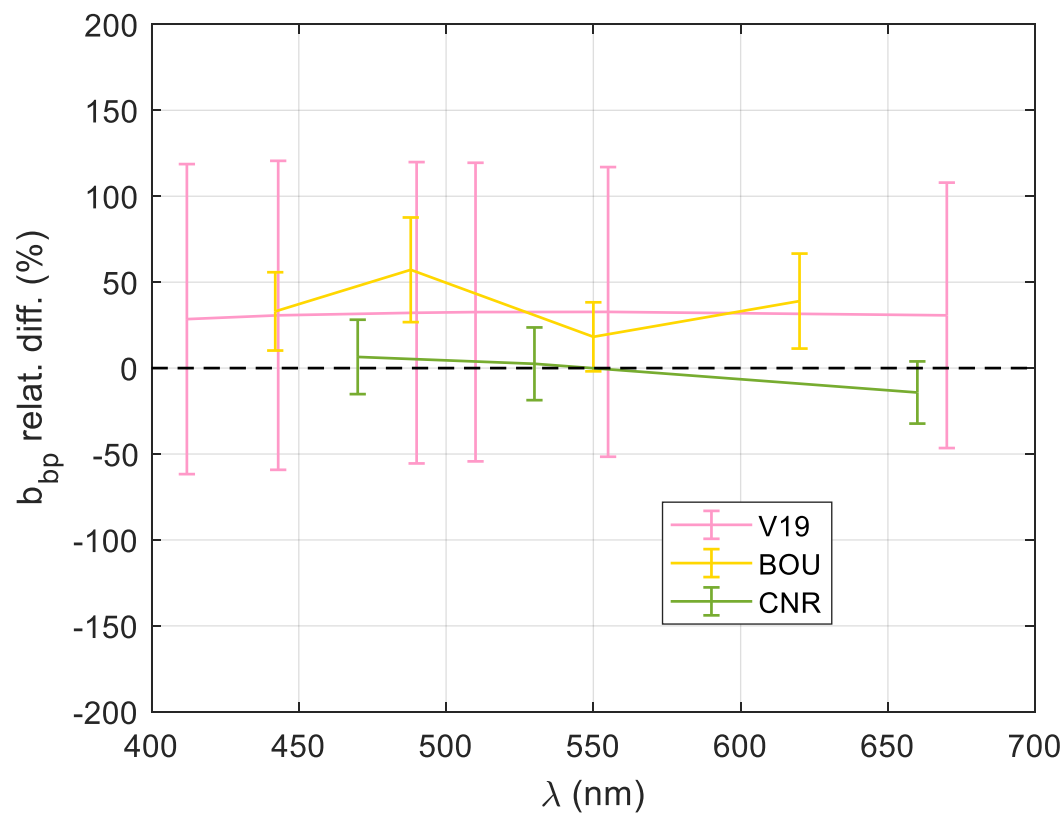

Figure A2. Relative differences between the $b_{\mathrm{bp}}$-QAA derived and in situ $b_{\mathrm{bp}}$ for each dataset with Raman scattering compensation. Data taken from Table 2. Pink, yellow and green lines refer to V19, BOU, and CNR data, respectively. 


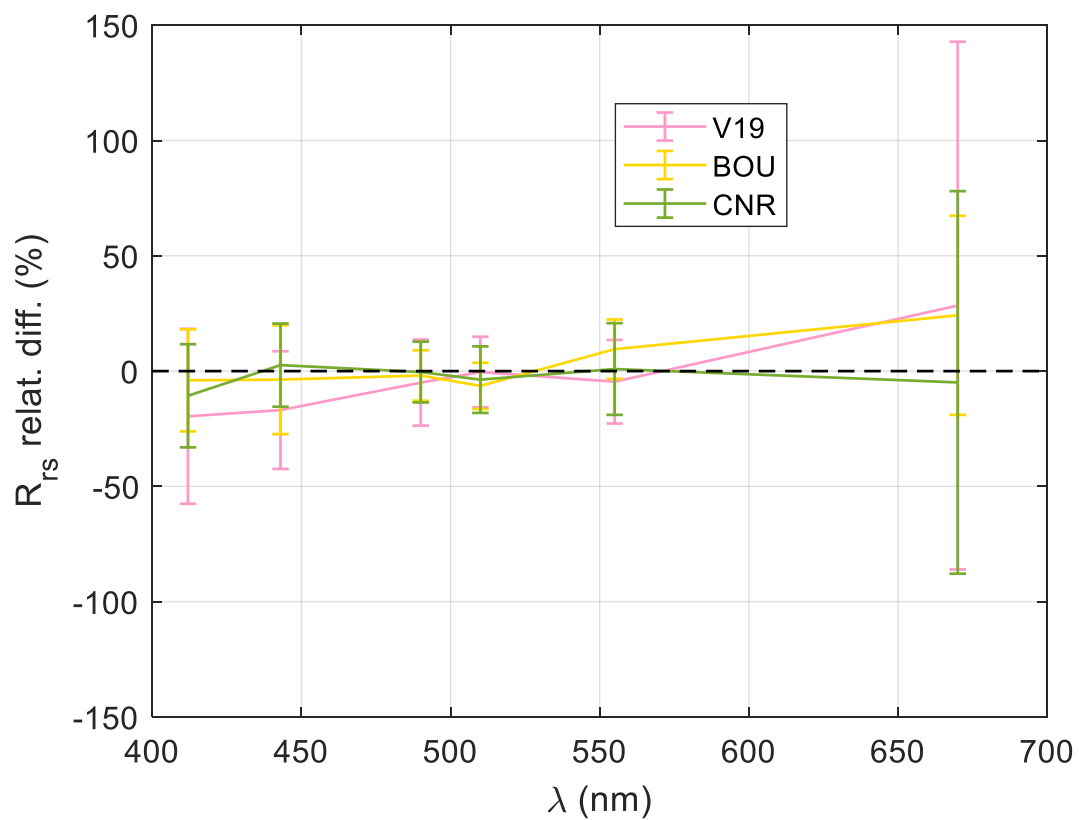

Figure A3. Relative differences between satellite CCI $\mathrm{R}_{\mathrm{rs}}$ and in situ $\mathrm{R}_{\mathrm{rs}}$ for each dataset. Data taken from Table 3. Pink, yellow, and green lines refer to V19, BOU, and CNR data, respectively.

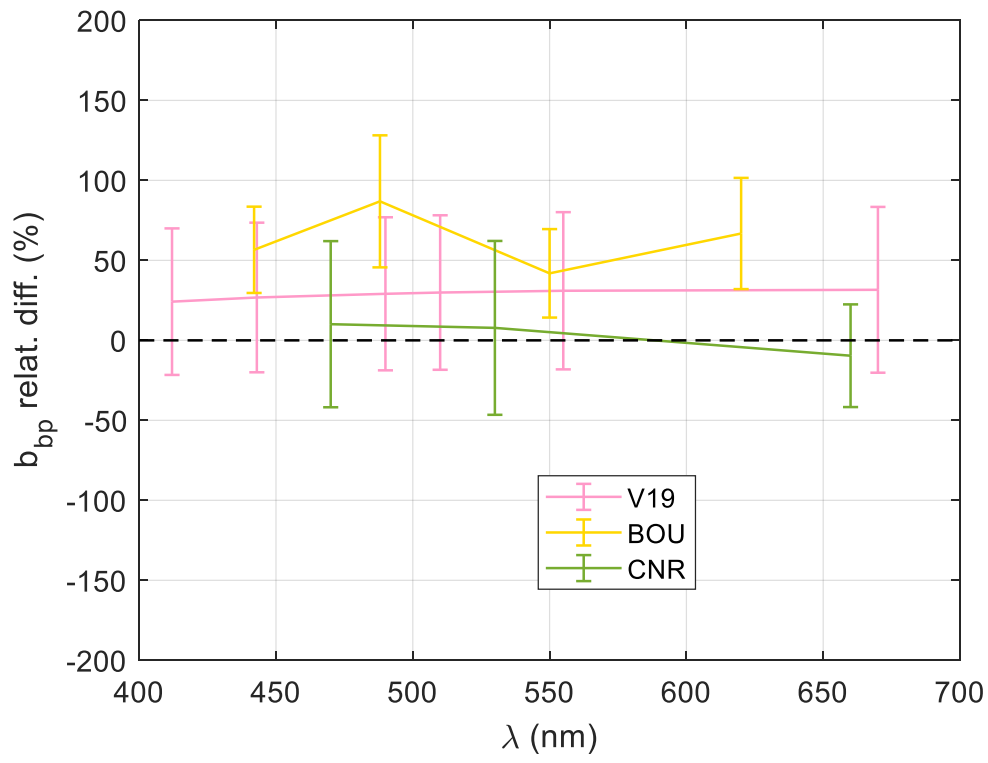

Figure A4. Relative difference between the QAA-derived $b_{b p}$ from satellite CCI $R_{r s}$ and in situ $b_{b p}$ for each dataset with Raman scattering compensation. Data taken from Table 1. Pink, yellow, and green lines refer to V19, BOU, and CNR data, respectively.

\section{References}

1. Behrenfeld, M.J.; Boss, E.; Siegel, D.A.; Shea, D.M. Carbon-based ocean productivity and phytoplankton physiology from space. Glob. Biogeochem. Cycles 2005, 19. [CrossRef]

2. Bellacicco, M.; Volpe, G.; Colella, S.; Pitarch, J.; Santoleri, R. Influence of photoacclimation on the phytoplankton seasonal cycle in the Mediterranean Sea as seen by satellite. Remote Sens. Environ. 2016, 184, 595-604. [CrossRef]

3. Lee, Z.; Carder, K.L.; Arnone, R.A. Deriving inherent optical properties from water color: A multiband quasi-analytical algorithm for optically deep waters. Appl. Opt. 2002, 41, 5755-5772. [CrossRef] [PubMed] 
4. Loisel, H.; Stramski, D.; Dessailly, D.; Jamet, C.; Li, L.; Reynolds, R.A. An Inverse Model for Estimating the Optical Absorption and Backscattering Coefficients of Seawater from Remote-Sensing Reflectance Over a Broad Range of Oceanic and Coastal Marine Environments. J. Geophys. Res. Oceans 2018, 123, 2141-2171. [CrossRef]

5. $\quad$ Brewin, R.J.W.; Sathyendranath, S.; Müller, D.; Brockmann, C.; Deschamps, P.-Y.; Devred, E.; Doerffer, R.; Fomferra, N.; Franz, B.; Grant, M.; et al. The Ocean Colour Climate Change Initiative: III. A round-robin comparison on in-water bio-optical algorithms. Remote Sens. Environ. 2015, 162, 271-294. [CrossRef]

6. Twardowski, M.S.; Boss, E.; Macdonald, J.B.; Pegau, W.S.; Barnard, A.H.; Zaneveld, J.R.V. A model for estimating bulk refractive index from the optical backscattering ratio and the implications for understanding particle composition in case I and case II waters. J. Geophys. Res. Oceans 2001, 106, 14129-14142. [CrossRef]

7. Slade, W.H.; Boss, E. Spectral attenuation and backscattering as indicators of average particle size. Appl. Opt. 2015, 54, 7264-7277. [CrossRef]

8. Organelli, E.; Dall'Olmo, G.; Brewin, R.J.W.; Tarran, G.A.; Boss, E.; Bricaud, A. The open-ocean missing backscattering is in the structural complexity of particles. Nat. Commun. 2018, 9, 5439. [CrossRef]

9. Stramski, D.; Kiefer, D.A. Light scattering by microorganisms in the open ocean. Prog. Oceanogr. 1991, 28, 343-383. [CrossRef]

10. Morel, A.; Ahn, Y.-H. Optics of heterotrophic nanoflagellates and ciliates: A tentative assessment of their scattering role in oceanic waters compared to those of bacterial and algal cells. J. Mar. Res. 1991, 49, 177-202. [CrossRef]

11. Stramski, D.; Boss, E.; Bogucki, D.; Voss, K.J. The role of seawater constituents in light backscattering in the ocean. Prog. Oceanogr. 2004, 61, 27-56. [CrossRef]

12. Thomalla, S.J.; Ogunkoya, A.G.; Vichi, M.; Swart, S. Using Optical Sensors on Gliders to Estimate Phytoplankton Carbon Concentrations and Chlorophyll-to-Carbon Ratios in the Southern Ocean. Front. Mar. Sci. 2017, 4. [CrossRef]

13. Loisel, H.; Bosc, E.; Stramski, D.; Oubelkheir, K.; Deschamps, P.-Y. Seasonal variability of the backscattering coefficient in the Mediterranean Sea based on satellite SeaWiFS imagery. Geophys. Res. Lett. 2001, 28, 4203-4206. [CrossRef]

14. Kostadinov, T.S.; Siegel, D.A.; Maritorena, S. Retrieval of the particle size distribution from satellite ocean color observations. J. Geophys. Res. Oceans 2009, 114. [CrossRef]

15. Kostadinov, T.S.; Milutinović, S.; Marinov, I.; Cabré, A. Carbon-based phytoplankton size classes retrieved via ocean color estimates of the particle size distribution. Ocean Sci. 2016, 12, 561-575. [CrossRef]

16. Behrenfeld, M.J.; O’Malley, R.T.; Boss, E.S.; Westberry, T.K.; Graff, J.R.; Halsey, K.H.; Milligan, A.J.; Siegel, D.A.; Brown, M.B. Revaluating ocean warming impacts on global phytoplankton. Nat. Clim. Chang. 2015, 6, 323-330. [CrossRef]

17. Bellacicco, M.; Volpe, G.; Briggs, N.; Brando, V.; Pitarch, J.; Landolfi, A.; Colella, S.; Marullo, S.; Santoleri, R. Global Distribution of Non-algal Particles From Ocean Color Data and Implications for Phytoplankton Biomass Detection. Geophys. Res. Lett. 2018, 45, 7672-7682. [CrossRef]

18. Martínez-Vicente, V.; Evers-King, H.; Roy, S.; Kostadinov, T.S.; Tarran, G.A.; Graff, J.R.; Brewin, R.J.W.; Dall'Olmo, G.; Jackson, T.; Hickman, A.E.; et al. Intercomparison of Ocean Color Algorithms for Picophytoplankton Carbon in the Ocean. Front. Mar. Sci. 2017, 4. [CrossRef]

19. Siegel, D.A.; Behrenfeld, M.J.; Maritorena, S.; McClain, C.R.; Antoine, D.; Bailey, S.W.; Bontempi, P.S.; Boss, E.S.; Dierssen, H.M.; Doney, S.C.; et al. Regional to global assessments of phytoplankton dynamics from the SeaWiFS mission. Remote Sens. Environ. 2013, 135, 77-91. [CrossRef]

20. Halsey, K.H.; Jones, B.M. Phytoplankton Strategies for Photosynthetic Energy Allocation. Annu. Rev. Mar. Sci. 2015, 7, 265-297. [CrossRef]

21. Mobley, C.D. Light and Water: Radiative Transfer in Natural Waters; Academic Press: Cambridge, MA, USA, 1994.

22. Lee, Z. Update of the Quasi-Analytical Algorithm (QAA_v6). Available online: http://www.ioccg.org/groups/ Software_OCA/QAA_v6_2014209.pdf (accessed on 22 December 2019).

23. Huot, Y.; Morel, A.; Twardowski, M.S.; Stramski, D.; Reynolds, R.A. Particle optical backscattering along a chlorophyll gradient in the upper layer of the eastern South Pacific Ocean. Biogeosciences 2008, 5, 495-507. [CrossRef] 
24. Brewin, R.J.W.; Dall'Olmo, G.; Sathyendranath, S.; Hardman-Mountford, N.J. Particle backscattering as a function of chlorophyll and phytoplankton size structure in the open-ocean. Opt. Express 2012, 20, 17632-17652. [CrossRef] [PubMed]

25. Mélin, F. Comparison of SeaWiFS and MODIS time series of inherent optical properties for the Adriatic Sea. Ocean Sci. 2011, 7, 351-361. [CrossRef]

26. Werdell, P.J.; Bailey, S.W. An improved in situ bio-optical data set for ocean color algorithm development and satellite data product validation. Remote Sens. Environ. 2005, 98, 122-140. [CrossRef]

27. Werdell, P.J.; Franz, B.A.; Lefler, J.T.; Robinson, W.D.; Boss, E. Retrieving marine inherent optical properties from satellites using temperature and salinity-dependent backscattering by seawater. Opt. Express 2013, 21, 32611-32622. [CrossRef] [PubMed]

28. Zheng, G.; Stramski, D.; Reynolds, R.A. Evaluation of the Quasi-Analytical Algorithm for estimating the inherent optical properties of seawater from ocean color: Comparison of Arctic and lower-latitude waters. Remote Sens. Environ. 2014, 155, 194-209. [CrossRef]

29. Pitarch, J.; Bellacicco, M.; Volpe, G.; Colella, S.; Santoleri, R. Use of the quasi-analytical algorithm to retrieve backscattering from in situ data in the Mediterranean Sea. Remote Sens. Lett. 2016, 7, 591-600. [CrossRef]

30. Bisson, K.M.; Boss, E.; Westberry, T.K.; Behrenfeld, M.J. Evaluating satellite estimates of particulate backscatter in the global open ocean using autonomous profiling floats. Opt. Express 2019, 27, 30191-30203. [CrossRef]

31. Sathyendranath, S.; Brewin, R.J.W.; Brockmann, C.; Brotas, V.; Calton, B.; Chuprin, A.; Cipollini, P.; Couto, A.B.; Dingle, J.; Doerffer, R.; et al. An Ocean-Colour Time Series for Use in Climate Studies: The Experience of the Ocean-Colour Climate Change Initiative (OC-CCI). Sensors 2019, 19, 4285. [CrossRef]

32. Bellacicco, M.; Cornec, M.; Organelli, E.; Brewin, R.J.W.; Neukermans, G.; Volpe, G.; Barbieux, M.; Poteau, A.; Schmechtig, C.; D'Ortenzio, F.; et al. Global Variability of Optical Backscattering by Non-algal particles from a Biogeochemical-Argo Data Set. Geophys. Res. Lett. 2019, 46, 9767-9776. [CrossRef]

33. Valente, A.; Sathyendranath, S.; Brotas, V.; Groom, S.; Grant, M.; Taberner, M.; Antoine, D.; Arnone, R.; Balch, W.M.; Barker, K.; et al. A compilation of global bio-optical in situ data for ocean-colour satellite applications-version two. Earth Syst. Sci. Data 2019, 11, 1037-1068. [CrossRef]

34. Antoine, D.; Chami, M.; Claustre, H.; d'Ortenzio, F.; Morel, A.; Bécu, G.; Gentili, B.; Louis, F.; Ras, J.; Roussier, E. BOUSSOLE: A Joint CNRS-INSU, ESA, CNES, and NASA Ocean Color Calibration and Validation Activity; NASA: Washington, DC, USA, 2006.

35. Bracaglia, M.; Volpe, G.; Colella, S.; Santoleri, R.; Braga, F.; Brando, V.E. Using overlapping VIIRS scenes to observe short term variations in particulate matter in the coastal environment. Remote Sens. Environ. 2019, 233, 111367. [CrossRef]

36. Zhang, X.; Hu, L.; He, M.-X. Scattering by pure seawater: Effect of salinity. Opt. Express 2009, 17, 5698-5710. [CrossRef] [PubMed]

37. Huber, P.J.; Ronchetti, E.M. Robust Statistics; John Wiley \& Sons: New York, NY, USA, 1981.

38. Moré, J.J.; Sorensen, D.C. Computing a Trust Region Step. SIAM J. Sci. Stat. Comput. 1983, 4, 553-572. [CrossRef]

39. Westberry, T.K.; Boss, E.; Lee, Z. Influence of Raman scattering on ocean color inversion models. Appl. Opt. 2013, 52, 5552-5561. [CrossRef]

40. Lee, Z.; Hu, C.; Shang, S.; Du, K.; Lewis, M.; Arnone, R.; Brewin, R. Penetration of UV-visible solar radiation in the global oceans: Insights from ocean color remote sensing. J. Geophys. Res. Oceans 2013, 118, 4241-4255. [CrossRef]

41. Antoine, D.; Guevel, P.; Desté, J.-F.; Bécu, G.; Louis, F.; Scott, A.J.; Bardey, P. The “BOUSSOLE” Buoy-A New Transparent-to-Swell Taut Mooring Dedicated to Marine Optics: Design, Tests, and Performance at Sea. J. Atmos. Ocean. Technol. 2008, 25, 968-989. [CrossRef]

42. Antoine, D.; d'Ortenzio, F.; Hooker, S.B.; Bécu, G.; Gentili, B.; Tailliez, D.; Scott, A.J. Assessment of uncertainty in the ocean reflectance determined by three satellite ocean color sensors (MERIS, SeaWiFS and MODIS-A) at an offshore site in the Mediterranean Sea (BOUSSOLE project). J. Geophys. Res. Oceans 2008, 113. [CrossRef]

43. Mélin, F.; Sclep, G. Band shifting for ocean color multi-spectral reflectance data. Opt. Express 2015, 23, 2262-2279. [CrossRef] 
44. Valente, A.; Sathyendranath, S.; Brotas, V.; Groom, S.; Grant, M.; Taberner, M.; Antoine, D.; Arnone, R.; Balch, W.M.; Barker, K.; et al. Inherent optical properties and diffuse attenuation coefficient aggregated within +/-6 nm of SeaWiFS, MODIS-AQUA, VIIRS, OLCI and MERIS bands, corrected Version 2019-06-12. In A Compilation of Global Bio-Optical in Situ Data for Ocean-Colour Satellite Applications_Version Two; Valente, A., Ed.; Pangaea: Bremen, Germany, 2019. [CrossRef]

45. Antoine, D.; Siegel, D.A.; Kostadinov, T.; Maritorena, S.; Nelson, N.B.; Gentili, B.; Vellucci, V.; Guillocheau, N. Variability in optical particle backscattering in contrasting bio-optical oceanic regimes. Limnol. Oceanogr. 2011, 56, 955-973. [CrossRef]

46. Organelli, E.; Bricaud, A.; Gentili, B.; Antoine, D.; Vellucci, V. Retrieval of Colored Detrital Matter (CDM) light absorption coefficients in the Mediterranean Sea using field and satellite ocean color radiometry: Evaluation of bio-optical inversion models. Remote Sens. Environ. 2016, 186, 297-310. [CrossRef]

47. Volpe, G.; Colella, S.; Brando, V.E.; Forneris, V.; La Padula, F.; Di Cicco, A.; Sammartino, M.; Bracaglia, M.; Artuso, F.; Santoleri, R. Mediterranean ocean colour Level 3 operational multi-sensor processing. Ocean Sci. 2019, 15, 127-146. [CrossRef]

48. Jackson, T.; Chuprin, A.; Sathyendranath, S.; Grant, M.; Zühlke, M.; Dingle, J.; Storm, T.; Boettcher, M.; Fomferra, N. Ocean Colour Climate Change Initiative (OC_CCI)—Interim Phase. Product User Guide, D3.4 PUG. 2019. Available online: https://esa-oceancolour-cci.org/sites/esa-oceancolour-cci.org/alfresco.php?file= a68aa514-3668-4935-9235-fca10f7e8bee\&name=OC-CCI-PUG-v4.1-v1.pdf (accessed on 22 December 2019).

49. Mélin, F.; Chuprin, A.; Grant, M.; Jackson, T.; Sathyendranath, S. Ocean Colour Climate Change Initiative (OC_CCI)_Phase Two; Ocean Colour Data Bias Correction and Merging D2.6; Plymouth Marine Laboratory: Plymouth, UK, 2016; Volume 35.

50. Lee, Z.; Huot, Y. On the non-closure of particle backscattering coefficient in oligotrophic oceans. Opt. Express 2014, 22, 29223-29233. [CrossRef]

51. Mélin, F.; Zibordi, G.; Berthon, J.-F. Assessment of satellite ocean color products at a coastal site. Remote Sens. Environ. 2007, 110, 192-215. [CrossRef]

52. Zibordi, G.; Voss, K.J.; Johnson, B.C.; Mueller, J.L. (Eds.) Protocols for Satellite Ocean Colour Data Validation: In Situ Optical Radiometry (Volume 3.0). In IOCCG Ocean Optics and Biogeochemistry Protocols for Satellite Ocean Colour Sensor Validation; IOCCG Protocol Series; IOCCG: Dartmouth, NS, Canada, 2019; Volume 3. [CrossRef]

53. Haltrin, V.I.; Kattawar, G.W.; Weidemann, A.D. Modeling of elastic and inelastic scattering effects in oceanic optics. In Proceedings of the Ocean Optics XIII (1997), Halifax, NS, Canada, 6 February 1997.

54. Dall'Olmo, G.; Westberry, T.K.; Behrenfeld, M.J.; Boss, E.; Slade, W.H. Significant contribution of large particles to optical backscattering in the open ocean. Biogeosciences 2009, 6, 947-967. [CrossRef] 